\title{
Trends and Projections of Breast Cancer in Saudi Arabia: A National Incidence Rates by Gender, Age, Nationality, and Years (1999-2014)
}

\author{
Anwar E Ahmed ${ }^{1,2 *}$,Yasmine A Zaatreh ${ }^{3}$, Aida A. Saad ${ }^{3}$, Mohammad Alkaiyat ${ }^{1,2,4}$, Tabrez Pasha ${ }^{1,2,4}$, Omar B. Da'ar $^{1,2}$, \\ Khaled Alkattan ${ }^{3}$, Abdul Rahman Jazieh ${ }^{1,2,4}$
}

${ }^{1}$ King Saud bin Abdulaziz University for Health Sciences, Riyadh, Saudi Arabia

${ }^{2}$ King Abdullah International Medical Research Center, Riyadh, Saudi Arabia

${ }^{3}$ College of Medicine, Alfaisal University, Riyadh, Saudi Arabia

${ }^{4}$ Oncology Department, Ministry of National Guard - Health Affairs, Riyadh, Saudi Arabia

Received: 制: December 15, 2018; Published: 鴊: January 02, 2019

*Corresponding author: Anwar E Ahmed, College of Public Health and Health Informatics, MC 2350, PO Box 22490 Riyadh, 11426, KSA, Saudi Arabia

\section{Abstract}

Background: Despite the fact that the incidence of breast cancer continues to increase in Saudi Arabia, we have yet to see a national report assessing the association between the incidence of breast cancer and patient characteristics. This study aimed to evaluate the incidence of breast cancer and its 2030 projection.

Methods: This national-level cohort study utilized the Cancer Registry of Saudi Arabia data that reported on breast cancer patients who diagnosed between 1999 and 2014 (the most recent report).

Results: The age-standardized incidence rate (ASIR) has increased over 15 years from 13.6/100,000 in 1999 to 22.7/100,000 in 2014 for the female population (an increase of $66.9 \%$ ). The strongest associations with breast cancer were found for gender (female vs. male: aIRR $=51.235$, $95 \%$ CI 42.576, 61.654), age $45-59$ years ( $45-59$ vs. < 30 years: aIRR $=18.517,95 \%$ CI 14.692, 23.338), age 30-44 years (30-44 vs. < 30 years: aIRR $=15.223,95 \%$ CI 12.140, 19.089), and Saudi nationality (Saudi vs. non-Saudi: aIRR = 2.417, 95\% CI 2.055, 2.843), and the year 2014 (2014 vs. 1999 : aIRR $=2.739,95 \%$ CI $1.768,4.241)$.

Conclusion: Our 15-year report indicates an upward trend of breast cancer in Saudi Arabia. There was evidence of the independent effects of old age, female gender, Saudi nationality, and the later years (2006-2014) on the increasing risk of breast cancer. These findings could have significant implications in establishing national breast cancer screening interventions to increase the rate of early detection.

Keywords: Breast Cancer; Incidence; Breast Cancer Screening; Age; Saudi Vision 2030

Abbreviations: ASIR: Age-Standardized Incidence Rate; SCR: Saudi Cancer Registry; IRB: Institutional Review Board; AIC: Akaike Information Criterion; AIRR: Adjusted Incidence Rate Ratios

\section{Introduction}

Breast cancer is classified as the most frequently diagnosed cancer site among women in Saudi Arabia [1-3], with its incidence continuing to increase rapidly during recent decades $[2,4]$, and it can occur in women at an early age [2,3,5-7]. The incidence appears to differ by geographic regions, with the highest incidence found in the eastern, central, and western regions of the country [7]. Breast cancer represents $28 \%$ of all newly diagnosed cancer sites among Saudi women $[2,8]$. Updated data is limited on national patterns and trends of breast cancer incidence in Saudi Arabia. While two reports utilized data available publically at the Saudi Cancer Registry webpage [2,7], both reports are limited by their descriptive nature. The national incidence of breast cancer has not previously been demonstrated in Saudi males in these studies. Furthermore, these studies excluded diagnosed patients of non-Saudi nationality.

Therefore, in this study we determined the overall incidence trends by including all breast cancer cases reported in Saudi 
Arabia. To date, no national-level study has ever been conducted to investigate breast cancer rates across gender, age, nationality, and time intervals. Exploring these factors may impact breast cancer management plans by instigating development of additional screening programs for the groups with high incidence rates. The aim of this surveillance data analysis was to assess the trends in breast cancer incidence in Saudi Arabia, and to determine whether high incidence correlates with gender, age, nationality, and the time. We also wanted to project the number of new breast cancer cases in 2030 .

\section{Methods}

This is a retrospective cohort review of breast cancer patients in Saudi Arabia who were reported by the Saudi Cancer Registry (SCR). The study obtained nationwide records from the SCR of breast cancer cases diagnosed from 1999 through 2014. (The 2003 incidence report has been excluded from our analysis because there was no available annual report for 2003.) We studied this period because it represents the most recent available data on breast cancer. The SCR monitors the occurrence of all cancer sites in the population of Saudi Arabia. The SCR was established in 1992 to serve as a resource for annual reports of new cases of cancer. All health facilities in Saudi Arabia periodically report newly detected cases of cancer to the SCR. Data were reported anonymously by the SCR for the purposes of privacy, confidentiality, and protection of patients' rights. We utilized aggregated data that were made available publicly at the Saudi Cancer Registry webpage (www. chs.gov.sa). The study authors obtained ethical approval from two independent Institutional Review Board (IRB) committees at AlFaisal University and the Ministry of National Guard Health Affairs (MNGHA), Riyadh, Saudi Arabia.

The breast cancer data (1999-2014, excluding 2003) were collected by two female medical students from Alfaisal University, and then reviewed and cross checked by the study authors. We extracted data on age, gender, nationality, and year of diagnosis. We classified age into five groups (age $<30$, age $30-44$, age $45-59$, age $60-64$, and age $\geq 65$ years). We gathered data on the main outcome, which is the number of new breast cancer cases reported annually (1999-2014, excluding 2003) in Saudi Arabia, and stratified according to gender, age groups, nationality, and year (1999-2014, excluding 2003).

\section{Statistical Analysis}

Analysis was carried out using the IBM SPSS statistical package (version 25, IBM Corporation, USA). The data were illustrated by frequency and percent (Table 1). Poisson and negative binomial and regression models were used to model the breast cancer incidence and its relation to patient characteristics. We compared the measures of adequacy of fit between these models to identify which model fits our data better. The comparison was made in terms of deviance (close to 1.0 indicates the better model), Akaike information criterion (AIC) (lower indicates a better model), and the log likelihood (large value indicates a better model). A p-value of (P) $\leq 0.05$ implied there was significant association. The unadjusted and adjusted incidence rate ratios (IRR and aIRR, respectively) and 95\% confidence intervals (95\% CI) were used to assess the strength of the association.

\section{Results}

A total of 174,701 incident cancer cases were diagnosed and analyzed between 1999 and 2014 in Saudi Arabia, and 24,103 (13.8\%) new cases of breast cancer were diagnosed during this period. Of the sample diagnosed with breast cancer, the female predominance was $98.3 \%$ compared with $1.7 \%$ in males (Table $1)$. The majority of breast cancer cases were identified in middleaged patients with ages between 30 and 59 years (76.4\%). The new cases of breast cancer continued to increase over time (19992014) in Saudi Arabia. In 1999, 831 new cases were identified with breast cancer, while 2,605 new cases were identified in 2014, an increase of 1,774 cases over a 15-year period. Table 2 shows the factors associated with the high incidence rate ratios (IRR) of breast cancer in Saudi Arabia. The unadjusted incidence rate was greater in the female gender, Saudis, age 30-44 years old, age 45-59 years old, age 60-64 years old, age $\geq 65$ years old, and later years (2005 to 2014). The multivariate negative binomial model (Table 2) demonstrated that the adjusted incidence rate was higher in females (adjusted incidence rate ratios ( (IRR) $=51.235, \mathrm{P}=0.001$ ), Saudis ( IRR $=2.417, \mathrm{P}=0.001$ ), age 30-44 years old ( $\mathrm{aIRR}=15.223$, $\mathrm{P}=0.001$ ), age 45-59 years old ( $\mathrm{aIRR}=18.517, \mathrm{P}=0.001$ ), age 60-64 years old ( IIRR $=12.107, \mathrm{P}=0.001$ ), age $\geq 65$ years old ( $\mathrm{aIRR}=6.522$, $\mathrm{P}=0.001$ ), and later years 2006 ( $\mathrm{aIRR}=1.579, \mathrm{P}=0.0045)$ to 2014 ( $\mathrm{aIRR}=2.739, \mathrm{P}=0.001)$.

Table 1: Characteristics of patients diagnosed with breast cancer in Saudi Arabia, 1999 and 2014 (N=24103).

\begin{tabular}{|c|c|c|c|}
\hline Characteristics & Levels & n & \% \\
\hline Gender & Male & 408 & 9.7 \\
\hline & Female & 23695 & 4.1 \\
\hline Age & Age $<30$ & 998 & 36.2 \\
\hline & Age $30-44$ & 8723 & 40.2 \\
\hline Age $45-59$ & 9662 & 7.2 \\
\hline & Age $60-64$ & 1744 & 12.3 \\
\hline
\end{tabular}

Cite this article: Anwar EA,Yasmine AZ, Aida AS, Mohammad A, Tabrez P, Omar B, et al. Trends and Projections of Breast Cancer in Saudi Arabia: A National Incidence Rates by Gender, Age, Nationality, and Years (1999-2014). Biomed J Sci \& Tech Res 12(4)-2019. BJSTR. MS.ID.002270. DOI: $10.26717 /$ BJSTR.2019.12.002270. 


\begin{tabular}{|l|l|l|l|}
\hline & Saudi & 17221 & 71.4 \\
\hline Year & 1999 & 831 & 3.4 \\
\hline & 2000 & 861 & 3.2 \\
\hline & 2001 & 762 & 3.6 \\
\hline & 2002 & 872 & 4.7 \\
\hline & 2004 & 1131 & 5.6 \\
\hline & 2005 & 1358 & 5.8 \\
\hline & 2006 & 1390 & 7.0 \\
\hline & 2007 & 1693 & 6.7 \\
\hline & 2008 & 1609 & 7.8 \\
\hline & 2009 & 1883 & 8.7 \\
\hline & 2010 & 2085 & 9.4 \\
\hline & 2011 & 2277 & 9.2 \\
\hline
\end{tabular}

Table 2: Factors associated with high incidence rates of breast cancer in Saudi Arabia, 1999 and 2014 (N=24103).

\begin{tabular}{|c|c|c|c|c|c|c|c|c|c|c|c|}
\hline \multirow[b]{2}{*}{ Factor } & \multirow[b]{2}{*}{ Ref. } & \multirow[b]{2}{*}{ B } & \multirow[b]{2}{*}{$\mathbf{P}$} & \multirow[b]{2}{*}{ IRR } & \multicolumn{2}{|c|}{$\begin{array}{c}95 \% \text { Wald } \\
\text { Confidence Interval } \\
\text { for IRR }\end{array}$} & \multirow[b]{2}{*}{ B } & \multirow[b]{2}{*}{$\mathbf{P}$} & \multirow[b]{2}{*}{ aIRR } & \multicolumn{2}{|c|}{$\begin{array}{c}95 \% \text { Wald } \\
\text { Confidence Interval } \\
\text { for aIRR }\end{array}$} \\
\hline & & & & & Lower & Upper & & & & Lower & Upper \\
\hline Female & Male & 4.064 & $0.001^{*}$ & 58.191 & 49.716 & 68.111 & 3.936 & $0.001^{*}$ & 51.235 & 42.576 & 61.654 \\
\hline Saudi & None & 0.915 & $0.001^{*}$ & 2.497 & 2.201 & 2.834 & 0.883 & $0.001^{*}$ & 2.417 & 2.055 & 2.843 \\
\hline Age $30-44$ & $<30$ & 2.858 & $0.001^{*}$ & 17.432 & 14.407 & 21.093 & 2.723 & $0.001^{*}$ & 15.223 & 12.14 & 19.089 \\
\hline Age 45-59 & $<30$ & 2.961 & $0.001^{*}$ & 19.309 & 15.96 & 23.361 & 2.919 & $0.001^{*}$ & 18.517 & 14.692 & 23.338 \\
\hline Age 60-64 & $<30$ & 2.347 & $0.001^{*}$ & 10.456 & 7.869 & 13.893 & 2.494 & $0.001^{*}$ & 12.107 & 8.563 & 17.118 \\
\hline Age $\geq 65$ & $<30$ & 1.825 & $0.001^{*}$ & 6.203 & 5.102 & 7.542 & 1.875 & $0.001^{*}$ & 6.522 & 5.081 & 8.372 \\
\hline 2014 & 1999 & 1.143 & $0.001^{*}$ & 3.135 & 2.22 & 4.427 & 1.007 & $0.001^{*}$ & 2.739 & 1.768 & 4.241 \\
\hline 2013 & 1999 & 1.115 & $0.001^{*}$ & 3.051 & 2.16 & 4.308 & 0.916 & $0.001^{*}$ & 2.5 & 1.614 & 3.874 \\
\hline 2012 & 1999 & 0.979 & $0.001^{*}$ & 2.661 & 1.883 & 3.759 & 0.929 & $0.001^{*}$ & 2.532 & 1.631 & 3.931 \\
\hline 2011 & 1999 & 1.008 & $0.001 *$ & 2.74 & 1.94 & 3.87 & 0.922 & $0.001^{*}$ & 2.515 & 1.62 & 3.905 \\
\hline 2010 & 1999 & 0.92 & $0.001^{*}$ & 2.509 & 1.776 & 3.545 & 0.848 & $0.001^{*}$ & 2.335 & 1.503 & 3.626 \\
\hline 2009 & 1999 & 0.818 & $0.001^{*}$ & 2.266 & 1.603 & 3.202 & 0.781 & $0.001^{*}$ & 2.184 & 1.4 & 3.407 \\
\hline 2008 & 1999 & 0.676 & $0.001^{*}$ & 1.965 & 1.388 & 2.782 & 0.825 & $0.001^{*}$ & 2.283 & 1.461 & 3.568 \\
\hline 2007 & 1999 & 0.712 & $0.001^{*}$ & 2.037 & 1.441 & 2.88 & 0.659 & $0.004^{*}$ & 1.933 & 1.24 & 3.015 \\
\hline 2006 & 1999 & 0.514 & $0.004^{*}$ & 1.673 & 1.182 & 2.366 & 0.457 & $0.045^{*}$ & 1.579 & 1.009 & 2.469 \\
\hline 2005 & 1999 & 0.491 & $0.006^{*}$ & 1.634 & 1.155 & 2.312 & 0.403 & 0.077 & 1.496 & 0.957 & 2.337 \\
\hline 2004 & 1999 & 0.308 & 0.082 & 1.361 & 0.961 & 1.927 & 0.342 & 0.137 & 1.408 & 0.897 & 2.209 \\
\hline 2002 & 1999 & 0.048 & 0.787 & 1.049 & 0.74 & 1.488 & 0.069 & 0.772 & 1.072 & 0.671 & 1.711 \\
\hline 2001 & 1999 & 0.038 & 0.834 & 1.039 & 0.724 & 1.491 & -0.011 & 0.962 & 0.989 & 0.615 & 1.589 \\
\hline 2000 & 1999 & 0.035 & 0.842 & 1.036 & 0.731 & 1.469 & -0.07 & 0.764 & 0.932 & 0.59 & 1.473 \\
\hline
\end{tabular}

The goodness of fit measures revealed that the negative binomial provided a better fit than the Poisson model: the deviance (negative binomial 0.905; Poisson regression 5.566), log likelihood (negative binomial -2487.589; Poisson regression 3842.922), and
AIC (negative binomial 5017.179; Poisson regression 7727.843). The forecast analysis in Figure 1 revealed that 4316 cases of breast cancer are projected to be diagnosed in 2030. 


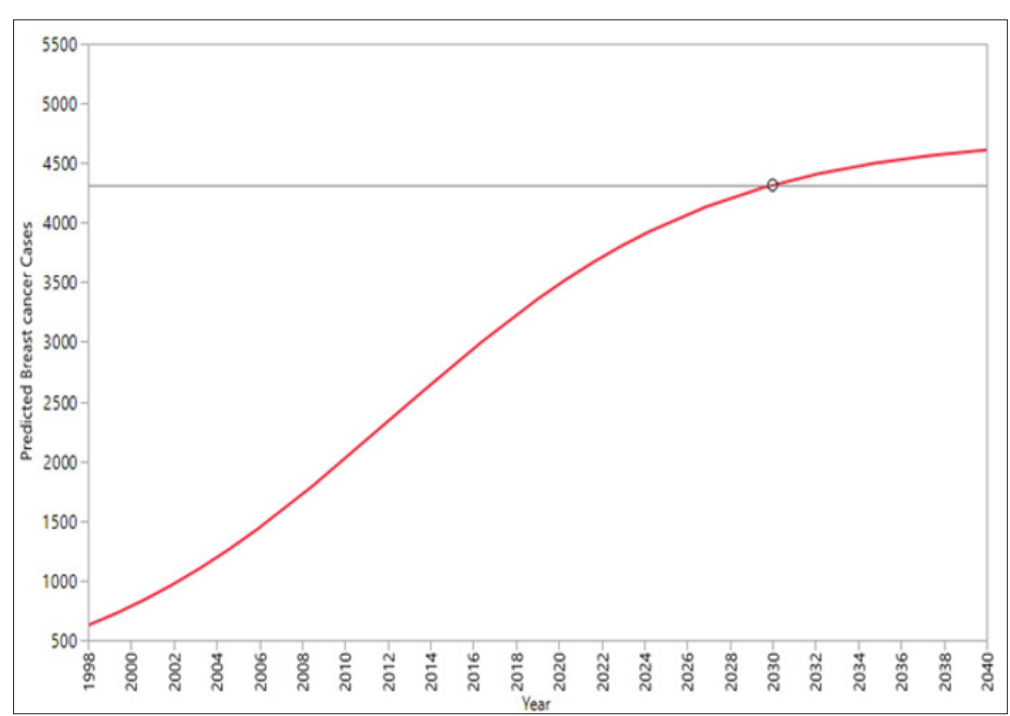

Figure 1: Breast cancer cases 2030 forecast in Saudi Arabia.

\section{Discussion}

This is the first national-level study of surveillance data that evaluated breast cancer incidence trends and its relation to patient characteristics in Saudi Arabia. The study covered a period of 15 years to assess trends in breast cancer cases nationwide. Breast cancer ranked top among women, accounting for $28.7 \%$ of all malignancies reported among females in Saudi Arabia in 2014. This is consistent with earlier international reports, where breast cancer is reported to be the most frequent cancer type diagnosed among females and is responsible for a large percent of all diagnosed malignancies [811]. The data suggest that the cases of breast cancer continuously increase as per our 2030 projection, 4316 cases are projected to be diagnosed in 2030. One must take into consideration that this projection was made according to populations during 1999-2014 and assuming no significant changes in terms of gender, age, and nationality distributions. The age-standardized incidence rate (ASIR) for the female population has increased over the 15 years from 13.6/100,000 in 1999 to 22.7/100,000 in 2014.

Despite the increase in ASIR over time, there is a need to increase the low-grade breast cancer incidence. The most recent ASIR found in Saudi Arabia was lower than the World Standard Population trends of 43.1 per 100,000 females in 2012 [12]. This difference could be attributed to lack of national breast cancerscreening programs to detect more low-grade cases in Saudi Arabia [13]. The effectiveness of routine screening for breast cancer could be faced with several barriers, such as cultural beliefs and social stigma [14]. Saudi Arabian studies report that large percentages of females never received breast mammography or performed breast self-examination, and this could be due to the poor knowledge of breast cancer $[15,16]$. High-quality national breast cancer assessment that takes into consideration cultural beliefs and social stigma is warranted to identify the most efficient and effective screening program. On the multivariable negative binomial analysis, the frequency of breast cancer tends to increase with the year of diagnosis (1999 to 2014). We assessed patient factors that may have the potential to drive the increase in incidence of breast cancer in Saudi Arabia.
In agreement with many studies [17-19], females are much more likely than males to have an increased risk of breast cancer. According to our study, breast cancer in males is infrequently diagnosed, accounting for $43 / 7130(0.6 \%)$ of all malignancies in males, whereas it accounted for 2562/8055(31.8\%) of all malignancies in females in 2014. These trends have not been reported elsewhere, as our study included both Saudis and nonSaudis. The adjusted incidence rate of breast cancer was compared by nationality. In Saudis, the incidence of breast cancer has more than doubled as compared to non-Saudis. It is likely that the wide variability of incidence of breast cancer between Saudis and nonSaudis is due to variation in gene expression and lifestyle [20]. Furthermore, females in Saudi Arabia are more challenged by high unemployment rates than males [21]. This may lead to a large percent of the non-Saudi workforce being males with or without family, which could have a greater effect on lowering breast cancer risk among non-Saudis. The incidence of breast cancer has been noted in all age groups, however, the greatest rise was noticed in middle-aged group (30-44 and 45-59 years old).

On the multivariable negative binomial analysis, women of ages 30-44 and 45-59 years old were associated with a higher rate of breast cancer incidence as compared to young women of ages $<30$ years old. This finding has been well documented in several studies [7,22-25], confirming that the incidence of breast cancer increases in the old age group with the peak incidence noticed in the middleaged group. Implementation of frequent routine screening in these age groups may improve early detection, increase low-grade cases, and this may have the potential to improve survival rates [26,27]. The high rate of breast cancer in women of age groups 30-44 and 4559 years could be explained by the widespread usage of hormone therapy to treat symptoms of menopause in these age groups, as it has been found to increase the risk of breast cancer [28-30]. This type of effect could be investigated in a prospective study to assess the effects of reducing hormone therapy use on dropping the incidence in these age groups. The main limitation that could be noted is that our study utilized open source national registry data with fewer demographic data, but no details of clinically relevant 
data such as use of hormone therapy, being postmenopausal, or history of breast cancer.

There is a need to modify national data collection standards on breast cancer to include clinically relevant data and improve the capacity of the breast cancer registry. Despite the limitation of this retrospective report, this is the first 15-year report to show national incidence and its correlation with gender, age, nationality, and time. Our study shows the incidence of breast cancer in Saudi Arabia was greater in the more recent years (2006-2014).

\section{Conclusion}

Our 15-year report indicates an upward trend of breast cancer in Saudi Arabia. There was statistical evidence of an independent effect of old age, female gender, Saudi nationality, and the later years (2006-2014) on the increasing risk of breast cancer. These findings could have significant implications on establishing, at the national level, breast cancer screening programs to improve early detection and increase low-grade cases. This includes routine selfexams, multiple periodic breast imaging screening, and improving awareness among targeted groups at high risk of breast cancer.

\section{References}

1. El Saghir NS, Khalil MK, Eid T, El Kinge AR, Charafeddine M, et al. (2007) Trends in epidemiology and management of breast cancer in developing Arab countries: a literature and registry analysis. International journal of surgery 5(4): 225-233.

2. Saggu S, Rehman H, Abbas ZK, Ansari AA (2015) Recent incidence and descriptive epidemiological survey of breast cancer in Saudi Arabia. Saudi medical journal 36(10): 1176-1180.

3. Al Rikabi A, Husain S (2012) Increasing prevalence of breast cancer among Saudi patients attending a tertiary referral hospital: a retrospective epidemiologic study. Croat Med J 53(3): 239-243.

4. Ibrahim EM, Zeeneldin AA, Sadiq BB, Ezzat AA (2008) The present and the future of breast cancer burden in the Kingdom of Saudi Arabia. Med Oncol 25(4): 387-393.

5. Makanjuola D, Alkushi A, Alzaid M, Abukhair O, Al Tahan F, et al. (2014) Breast cancer in women younger than 30 years: prevalence rate and imaging findings in a symptomatic population. Pan Afr Med J 19: 35.

6. Albasri A, Hussainy AS, Sundkji I, Alhujaily A (2014) Histopathological features of breast cancer in Al-Madinah region of Saudi Arabia. Saudi Med J 35(12): 1489-1493.

7. Alghamdi IG, Hussain II, Alghamdi MS, El Sheemy MA (2013) The incidence rate of female breast cancer in Saudi Arabia: an observational descriptive epidemiological analysis of data from Saudi Cancer Registry 2001-2008. Breast Cancer: Targets and Therapy 5: 103-109.

8. (2017) Cancer Incidence Report Saudi Arabia 2014. Saudi Cancer Registry (SCR).

9. Lakkis NA, Adib SM, Hamadeh G, El Jarrah R, Osman MH (2017) Sociological Transition and Breast Cancer in the Arab World: The Experience of Lebanon. Asian Pacific journal of cancer prevention: APJCP 18(5): 1357-1364.

10. Jara Lazaro AR, Thilagaratnam S, Tan PH (2010) Breast cancer in Singapore: some perspectives. Breast cancer 17(1): 23-28.

11. Wu CX, Zheng Y, Bao PP, Huang ZZ, Zhang ML (2017) Analysis of the patterns of female breast cancer incidence in Shanghai, 2003-2012. Zhonghua yu fang yi xue za zhi [Chinese journal of preventive medicine] 51(8): 692-697.

12. (2012) International Agency for Research on Cancer. GLOBOCAN 2012: estimated cancer incidence, mortality and prevalence worldwide in 2012.
13. Al Mulhim FA, Syed A, Bagatadah WA, Al Muhanna AF (2015) Breast cancer screening programme: experience from Eastern Province, Saudi Arabia/Programme de depistage du cancer du sein: experience de la province orientale en Arabie saoudite. East Mediterr Health J 21(2): 111-119.

14. Abdel Aziz SB, Amin TT, Al Gadeeb MB, Alhassar AI, Al Ramadan A, et al. (2017) Perceived barriers to breast cancer screening among Saudi women at primary care setting. Asian Pacific journal of cancer prevention: APJCP 18(9): 2409-2417.

15. Al Zalabani AH, Alharbi KD, Fallatah NI, Alqabshawi RI, Al Zalabani AA, et al. (2018) Breast cancer knowledge and screening practice and barriers among women in Madinah, Saudi Arabia. Journal of Cancer Education 33(1): 201-207.

16. Amin TT, Al Mulhim AR, Al Meqihwi A (2009) Breast cancer knowledge, risk factors and screening among adult Saudi women in a primary health care setting. Asian Pac J Cancer Prev 10(1): 133-138.

17. Manoharan N, Nair O, Shukla NK, Rath GK (2017) Descriptive Epidemiology of Female Breast Cancer in Delhi, India. Asian Pacific journal of cancer prevention: APJCP 18(4): 1015-1018.

18. Sipetic Grujicic S, Murtezani Z, Ratkov I, Grgurevic A, Marinkovic J, et al. (2013) Comparison of male and female breast cancer incidence and mortality trends in Central Serbia. Asian Pacific Journal of Cancer Prevention 14(10): 5681-5685.

19. Ly D, Forman D, Ferlay J, Brinton LA, Cook MB (2013) An international comparison of male and female breast cancer incidence rates. International journal of cancer 132(8): 1918-1926.

20. Al Kuraya K, Schraml P, Sheikh S, Amr S, Torhorst J, et al. (2005) Predominance of high-grade pathway in breast cancer development of Middle East women. Modern Pathology 18(7): 891-897.

21. (2016) Saudi Arabia Labor Market Report.

22. Alghamdi IG, Hussain II, Alghamdi MS, El Sheemy MA (2013) The incidence rate of female breast cancer in Saudi Arabia: an observational descriptive epidemiological analysis of data from Saudi Cancer Registry 2001-2008. Breast Cancer: Targets and Therapy 5: 103-109.

23. Yang L, Sun TT, Wang N (2012) The incidence and mortality trends of female breast cancer in Beijing, China: between 2004 and 2008. Zhonghua yu fang yi xue za zhi [Chinese journal of preventive medicine] 46(11): 1009-1014.

24. Dikshit RP, Yeole BB, Nagrani R, Dhillon P, Badwe R, et al. (2012) Increase in breast cancer incidence among older women in Mumbai: 30-year trends and predictions to 2025. Cancer Epidemiology 36(4): e215-220.

25. Halder A, Morewya J, Watters DA (2001) Rising incidence of breast cancer in Papua New Guinea. ANZ journal of surgery 71(10): 590-593.

26. Møller H, Sandin F, Bray F, Klint $\AA$, Linklater KM, et al. (2010) Breast cancer survival in England, Norway and Sweden: a population-based comparison. International journal of cancer 127(11): 2630-2638.

27. Mohd NT, Yip CH, Mohamed I (2008) Survival analysis of Malaysian women with breast cancer: results from the University of Malaya Medical Centre. Asian Pacific journal of cancer prevention: APJCP 9(2): 197-202.

28. Balamurugan A, Im L, Reeve G, Mehta P, Bates JH (2009) Incidence of female breast cancer in Arkansas: are we following the national trend? The Journal of the Arkansas Medical Society 105(12): 283-284.

29. Van Luijt PA, Heijnsdijk EA, Van Ravesteyn NT, Hofvind S, De Koning HJ (2017) Breast cancer incidence trends in Norway and estimates of overdiagnosis. Journal of medical screening 24(2): 83-91.

30. Suhrke P, Mæhlen J, Zahl PH (2012) Hormone therapy use and breast cancer incidence by histological subtypes in Sweden and Norway. The breast journal 18(6): 549-556.

Cite this article: Anwar EA,Yasmine AZ, Aida AS, Mohammad A, Tabrez P, Omar B, et al. Trends and Projections of Breast Cancer in Saudi Arabia: A National Incidence Rates by Gender, Age, Nationality, and Years (1999-2014). Biomed J Sci \& Tech Res 12(4)-2019. BJSTR. MS.ID.002270. DOI: $10.26717 /$ BJSTR.2019.12.002270. 
ISSN: 2574-1241

DOI: $10.26717 / B J S T R .2019 .12 .002270$

Anwar E Ahmed. Biomed J Sci \& Tech Res

(C) This work is licensed under Creative

Submission Link: https://biomedres.us/submit-manuscript.php

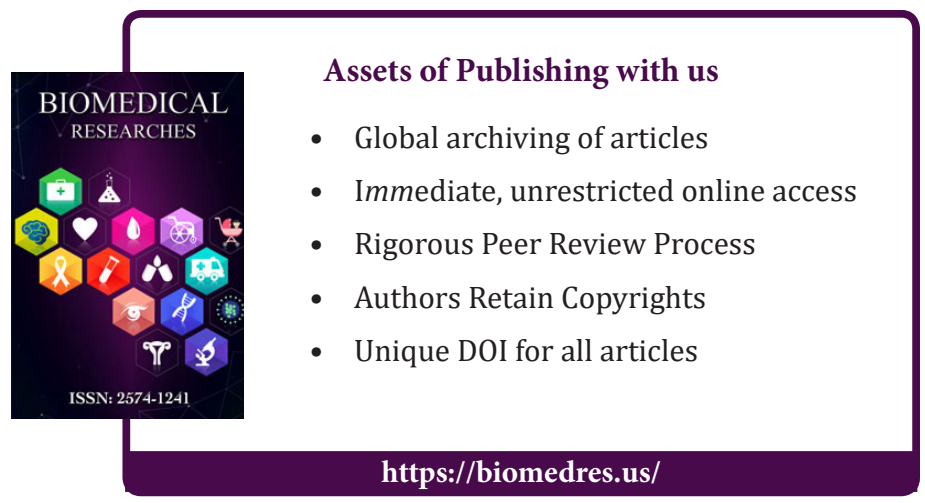

